\title{
Scientific authorship: a primer for researchers
}

\author{
Olena Zimba ${ }^{1}$, Armen Yuri Gasparyan ${ }^{2}$ \\ ${ }^{1}$ Department of Internal Medicine No. 2, Danylo Halytsky Lviv National Medical University, Lviv, Ukraine \\ 2Departments of Rheumatology and Research and Development, Dudley Group NHS Foundation Trust (Teaching Trust \\ of the University of Birmingham, UK), Russells Hall Hospital, Dudley, West Midlands, United Kingdom
}

\begin{abstract}
The International Committee of Medical Journal Editors (ICMJE) proposed the authorship criteria which can be employed by medics and allied specialists. Scholars who substantively contribute to research and writing, revise, approve final drafts for target journal submissions, and take responsibility for all aspects of the work deserve authorship. Increasing awareness of the ICMJE criteria, incorporating related points in journal instructions, and enforcing them in daily practice may have positive impact for healthcare. Instances of inappropriate authorship are ethical transgressions which can be avoided by editors employing strategies of author profile evaluations. There are several platforms for recording author accomplishments which may improve the discoverability of scholarly works and prevent unethical conduct.

Most publishers advise authors to submit their Open Researcher and Contributor IDs (ORCID) at the manuscript submission. Other identifiers, such as Twitter handles, are also emerging as tools to stimulate post-publication communication and increase authors' accountability for published articles.
\end{abstract}

Key words: authorship, publishing, publication ethics, rheumatology.

\section{Introduction}

Scientific authorship is based on principles of contribution, responsibility, and credit [1]. Some experts additionally advocate for equity, diversity, and inclusion to avoid gender and country-based biases and endorse the concept of equal opportunities for all able contributors [2]. Improving awareness of authorship norms may add to the quality of research and prevent research and publication misconduct [3].

The issue of authorship is becoming more complex in the time of the COVID-19 pandemic and global crisis $[4,5]$, affecting established research infrastructure and career opportunities and mandating switch to online collaboration. Early-career researchers are now facing challenges with motivation and involvement in influential studies [6]. Renewed initiatives are particularly warranted in research-intensive fields, such as rheumatology and immunology, to adapt to the new realities of cross-country and cross-disciplinary collaborations to re-evaluate antiinflammatory drugs and antiviral vaccines. More atten- tion to the issue of authorship in these fields is also required to ensure the crediting of those who meet certain authorship criteria and contribute to the science growth.

\section{Authorship criteria}

Defining authorship and employing strategies for verifying author qualifications distinguish ethical journals from substandard, or "predatory", journals [7]. Responsible journal editors and publishers alike regularly update their instructions for employing mechanisms of reporting author roles and preventing instances of inappropriate authorship [8].

The absolute majority of medical, biomedical, and allied journals currently declare the adherence to the International Committee of Medical Journal Editors (ICMJE) authorship criteria, mandating substantive contribution (1), participation in the manuscript revision (2), its approval for submission to a target journal (3), and responsibility for all aspects of the work (4) [9]. The main requirements are to fulfil all four criteria to be credited

Address for correspondence:

Olena Zimba, Department of Internal Medicine No. 2, Danylo Halytsky Lviv National Medical University, 1 Uzhhorodska St., 79010 Lviv, Ukraine, e-mail: zimbaolena@gmail.com

Submitted: 25.11.2020; Accepted: 02.12.2020 
as authors and acknowledge non-author contributions, such as language editing and other services offered by commercial editing agencies [10]. The agreement to take responsibility for all aspects of the scholarly work is perhaps the most critical and not entirely clear to some authors [11]. This criterion was introduced by the ICMJE in 2013 to curb the problems with inappropriate crediting for technical assistance, funding, language editing, statistical analyses, and other types of support in the absence of responsibility for all aspects of the work and (un)intentional wrongdoings [12]. Notably, technical (non-intellectual) contributions and financial support cannot justify an addition to the author bylines [13].

Biomedical journal editors, particularly those who process submissions from non-Anglophone countries and emerging professional societies, should implement mechanisms to increase the awareness of the ICMJE criteria and avoid instances of unethical authorship [14]. In this regard, an analysis of 296 names listed as authors of a top Iranian journal demonstrated that $37 \%$ of them did not meet the ICMJE criteria ("guest" authors) [15]. A large survey of physical medicine and rehabilitation specialists who published their research in the top specialist journals $(n=246)$ revealed that $45 \%$ of the respondents were unaware of the ICMJE authorship guidelines and 30\% were unaware of what constitutes honorary authorship [16].

Ideally, author contributions, order, and responsibilities throughout the publishing and post-publication communication should be defined at the start of research [17]. Such an approach may prevent human errors and misleading ethics notes in published articles.

Non-medical journal editors may adapt and enforce the adherence to the ICMJE authorship criteria, crediting those with substantive contributions [18]. Alternatively, they may refer to the Council of Science Editors (CSE) definitions and procedures that aim to assign authorship to persons with "sufficient" scholarly contributions. The CSE also recommends to identify roles of all co-authors and inform readers of the same [19].

Finally, all stakeholders in science communication are advised to familiarize with the updated ethics statements of the Committee on Publication Ethics (COPE)

Table I. Common instances of inappropriate authorship

\begin{tabular}{|lr|}
\hline Ethical misconduct & Involved individuals \\
\hline Guest authorship & Senior researchers \\
\hline Gift authorship & Collaborating fellows \\
\hline Ghost authorship & Industry-sponsored medical writers \\
\hline Paid authorship & Clients of commercial editing \\
& agencies \\
\hline Denial of authorship & Junior research fellows and students \\
\hline
\end{tabular}

that prioritize strategies to identify authors and their contributions and manage related disputes [20].

\section{Creative ideas and authorship order}

Although the current taxonomy of author contributions, which is employed by some publishers and journals, is sufficiently detailed and quantifiable [21], journal editors should not overlook the importance of immeasurable creative ideas. Traditionally, such ideas and overall intellectual input bring about the main credit in multi-authored research and review articles [22]. Ideas formulated as scientific hypotheses often result in soloauthored articles which are increasingly published in the time of the COVID-19 pandemic [23, 24].

The sequence of author names on article bylines is often determined by established global and local crediting norms, level of contribution, and academic discipline $[25,26]$. Traditionally, the first authorship is reserved for senior research fellows, those who secure funds, or administrators in post-Socialist countries. The same actors are listed last in most developed and Western countries. The first and last places on the bylines are often viewed as the most important in the context of technical and conceptual contributions. The first and last author entries are often processed by grant funding agencies and bibliographic databases. One of the rational and globally acceptable approaches to the authorship order is based on listing author names in declining order, i.e. those with the greatest contributions are listed first and followed by those with declining contributions [25, 27, 28].

Journal editors often process manuscripts with cofirst authors who may jointly benefit from their privileged place and claim their status during the academic promotion. Editorial policies of designating co-first authorship vary across journals since there are no universally acceptable instructions [29]. By properly denoting co-first authorship, editors may facilitate searches through online databases which should adjust their options to the growing trend in authorship [30].

\section{Instances of inappropriate authorship}

Inappropriate (honorary) authorship is a frequently reported publication ethics violation (Table I). In obvious cases of misconduct, individuals with minimal or no scholarly contributions are credited as authors. No any journal is immune to this transgression which is confounded by the unawareness of acceptable norms and inadequate editorial strategies. Numerous reports have pointed to honorary authorship even in articles of flagship journals due to corresponding authors' irresponsible conduct [31]. 
A landmark survey involving 630 corresponding authors of high-impact general medical journals revealed the following descending prevalence of honorary authorship: $25 \%$ in original research reports, $15 \%$ in reviews, and $11.2 \%$ in editorials [32]. A recent large survey of 3859 scholars demonstrated that $74 \%$ of respondents had been involved in a study where someone was added as a co-author without substantive contribution (honorary authorship) and 34\% had witnessed the opposite not listing a co-author despite substantive contribution (ghost writing) [33]. And when asked about the widely publicized ICMJE authorship criteria, only $74 \%$ confirmed their awareness.

Honorary authorship may present in different forms. An extreme case of the violation involves non-professionals who lack any knowledge in the subject like kids of influential administrators who abuse their power and fabricate profiles of their family members [34]. Members of research groups and collaborating centers may be involved in the so-called gift authorship by unethically assigning authorship to colleagues and expecting a reciprocal attitude from them [1]. Senior researchers and administrators with impressive profiles can be listed as "guest" authors in an attempt to increase the chances of the manuscript acceptance and publication [1].

Finally, "paid" authorship is offered by some predatory journals that sell authorship to individuals who wish to pay and unethically boost their publication records [35]. Such a predatory practice has surfaced in the times of mass proliferation of open-access journals and commercial editing agencies that offer their services in violation of established ethical norms. Importantly, most articles with paid authorship turned to be fabricated and published with "fake" reviews [36].

Sophisticated forms of misconduct include instances of guest authorship and ghost writing. In such cases, eminent scientists appear as lead authors in articles drafted by industry-sponsored medical "ghost" writers who hide their identities. Related articles often violate authorship and conflicts of interest disclosure norms and contain misleading drug information that may have dire consequences for healthcare [37, 38].

Finally, contributors with substantive input to research and writing may encounter the denial to be credited as authors [39]. The denial often affects junior research fellows and students who satisfy acceptable authorship criteria but judged unsuitable of scholarly credits [40]. Journal editors processing manuscripts from research environments where denial of authorship is possible due to subjective reasons, such as interpersonal conflicts and internal policies, should ask all listed authors to disclose their contributions and reassure that no-one deserving authorship credit has been denied such a privilege.

\section{Author identifiers}

Author identifiers and online profiling platforms play several important roles. One of the basic functions of such e-links is to distinguish scholars with identical names and help journal editors to increase visibility of scholarly contributions [41]. Assigning identifiers to non-Anglophone authors with variably spelled, misplaced, and missing names may prevent technical mistakes and avoid losing their article records in bibliographic databases [42]. In the era of digitization and open access, author identifiers are essential for making scholarly accomplishments more discoverable by cross-linking individual records with digital platforms, libraries, and editorial management systems [43, 44].

Since its launch in 2012, Open Researcher and Contributor ID (ORCID; https://orcid.org/) has become a universal and multifunctional tool for increasing visibility of author profiles and their scholarly contributions. As of November 23, 2020, the number of the registered users is $10,091,759$. Any scholar may freely register with the ORCID platform and maintain a persistent online profile for life. The main advantage of the platform is its ease of registration, safety and accuracy of data recording, and availability of options for listing author, reviewer, and editor accomplishments (Table II). ORCID IDs are now endorsed and integrated with numerous funding agencies, bibliographic databases and search platforms, reviewer crediting platform (Publons; http://publons.com/), and social media, enabling comprehensive evaluation of the ID holders' background and current scientific interests.

Table II. Some advantages and limitations of Open Researcher and Contributor ID (ORCID)

\begin{tabular}{|lr|}
\hline Advantages & \multicolumn{1}{c|}{ Limitations } \\
\hline $\begin{array}{l}\text { Non-proprietary service } \\
\text { for listing various individual } \\
\text { academic activities }\end{array}$ & $\begin{array}{r}\text { Lack of photographs, videos, } \\
\text { and article full texts }\end{array}$ \\
\hline $\begin{array}{l}\text { Ease of registration } \\
\text { Closed or outdated profiles } \\
\text { of some users }\end{array}$ \\
\hline $\begin{array}{l}\text { initiative } \\
\text { Disambiguation of author } \\
\text { names }\end{array}$ \\
\hline $\begin{array}{l}\text { Integration with numerous } \\
\text { scholarly platforms, } \\
\text { databases, and social media }\end{array}$ \\
\hline $\begin{array}{l}\text { Transparency and validity } \\
\text { of scholarly activities }\end{array}$ \\
\hline
\end{tabular}


Journal editors employ these IDs to pick peer reviewers and display editorial board member activities [45]. Importantly, non-Anglophone scholars may benefit a lot from the ORCID initiative by increasing transparency and validity of their academic activities [46].

Perhaps the main limitation of the ORCID initiative is the unavailability of scholars' photographs, video clips, interaction tools, and full-text repository, which are available on digital repositories and platforms for generating academic curriculum vitae such as ResearchGate (https://www.researchgate.net/). Also, some registrants may avoid publicly sharing their information, limiting the use of their IDs for scholarly evaluation purposes.

Listing several IDs with publicly available information may partly overcome limitations of ORCID IDs. Relevant examples are Scopus Author ID, PubMed list of articles, and Publons profile with merged Web of Science entries, which are now widely employed by journal editors for displaying academic profiles of their board members.

There are also successful precedents of listing author Twitter handles alongside emails and ORCID IDs in their articles for post-publication interactions with readers and followers. One of the relevant examples is Academic Medicine where corresponding author Twitter handles are increasingly listed in the published articles. Given the global use of Twitter for scholarly communication and dissemination of journal updates [47], it is expected that author Twitter handles will soon appear in most peer-reviewed journals. Listing author Twitter handles may in crease the responsibility for post-publication communication and overall accountability for published articles.

\section{Conclusions}

Improving awareness of ethical authorship and updating related journal instructions may help fairly credit individuals who deserve authorship. Perceptions of scholarly contributions and authorship criteria may vary across academic disciplines. However, adapting and adhering to the authorship recommendations of the ICMJE, CSE and COPE may curb numerous ethical problems.

Journal editors should employ strategies for evaluating author profiles and integrating their digital identifiers with published works. Authors, in turn, should familiarize with acceptable authorship criteria and fulfil their functions at pre- and post-publication stages. By adhering to authorship norms, editors and authors may prevent other forms of misconduct and ensure the integrity of published contents.

\section{Comments}

All are invited to watch the meeting on Facebook channel of the Reumatologia/Rheumatology journal, the official edition of the National Institute of Geriatrics, Rheumatology and Rehabilitation and Polish Society for Rheumatology at @Reumatologial

https://www.facebook.com/ReumatologiaJ/

This article overviews authorship criteria, author identifiers and online profiling platforms, common instances of inappropriate authorship, and suggests options to solve related problems by authors, reviewers, and editors of scholarly journals. This is the first review in a series of articles devoted to scientific writing and editing. Related topics were discussed during the twoday online workshop titled "Good practices in the writing of scientific articles" organized under the patronage of the journal Reumatologia on 18 and 19 November 2020.

\section{Editorial Team of Reumatologia}

The authors declare no conflict of interest.

\section{References}

1. Gasparyan AY, Ayvazyan L, Kitas GD. Authorship problems in scholarly journals: considerations for authors, peer reviewers and editors. Rheumatol Int 2013; 33: 277-284.

2. Rößler DC, Lötters S, Da Fonte LFM. Author declaration: have you considered equity, diversity and inclusion? Nature 2020; 584: 525, DOI: 10.1038/d41586-020-02429-8.

3. Donev D. New Developments in Publishing Related to Authorship. Pril (Makedon Akad Nauk Umet Odd Med Nauki) 2020; j/prilozi.ahead-of-print/prilozi-2020-0015/prilozi-2020-0015. xml, DOI: 10.2478/prilozi-2020-0015 [Online ahead of print].

4. Gewin V. The career cost of COVID-19 to female researchers, and how science should respond. Nature 2020; 583: 867-869, DOI: 10.1038/d41586-020-02183-X.

5. Andersen JP, Nielsen MW, Simone NL, et al. COVID-19 medical papers have fewer women first authors than expected. elife 2020; 9: e58807, DOI: 10.7554/eLife.58807.

6. Hunt JE. Being vulnerable. eLife 2020; 9: e59285, DOI: 10.7554/ elife.59285.

7. American Medical Writers Association; European Medical Writers Association; International Society for Medical Publication Professionals. AMWA-EMWA-ISMPP joint position statement on predatory publishing. Curr Med Res Opin 2019; 35: 1657-1658, DOI: 10.1080/03007995.2019.1646535.

8. Gasparyan AY, Yessirkepov M, Voronov AA, et al. Updated Editorial Guidance for Quality and Reliability of Research Output. J Korean Med Sci 2018; 33: e247, DOI: 10.3346/jkms.2018.33.e247.

9. Minshew LM, McLaughlin JE. Authorship Considerations for Publishing in Pharmacy Education Journals. Am J Pharm Educ 2019; 83: 7463, DOI: 10.5688/ajpe7463.

10. Misra DP, Agarwal V. Integrity of clinical research conduct, reporting, publishing, and post-publication promotion in rheumatology. Clin Rheumatol 2020; 39: 1049-1060, DOI: 10.1007/ s10067-020-04965-0. 
11. Caplan A, Badylak SF, Caplan Al, et al. Author Accountability in Biomedical Research. Stem Cells Dev 2018; 27: 1671-1673, DOI: 10.1089/scd.2018.0214

12. Misra DP, Ravindran V, Agarwal V. Integrity of Authorship and Peer Review Practices: Challenges and Opportunities for Improvement. J Korean Med Sci 2018; 33: e287, DOI: 10.3346/ jkms.2018.33.e287.

13. Caro JJ. Let's Make Sure We Are Doing Authorship Right. Value Health 2020; 23: 889-890, DOI: 10.1016/j.jval.2020.03.011.

14. Palla IA, Singson M, Thiyagarajan S. A comparative analysis of retracted papers in Health Sciences from China and India. Account Res 2020; 27: 401-416, DOI: 10.1080/08989621.2020.1754804.

15. Ghajarzadeh M. Guest authors in an Iranian journal. Dev World Bioeth 2014; 14: 15-19, DOI: 10.1111/dewb.12002.

16. Rajasekaran S, Shan RLP, Finnoff JT. Honorary authorship: frequency and associated factors in physical medicine and rehabilitation research articles Arch Phys Med Rehabil 2014; 95 418-428, DOI: 10.1016/j.apmr.2013.09.024.

17. Deora H. Authorship for Early Scientific Researchers: Ethics and Responsibility. World Neurosurg 2020; 134: 510-511, DOI 10.1016/j.wneu.2019.11.087

18. Kumar S. Ethical Concerns in the Rise of Co-Authorship and Its Role as a Proxy of Research Collaborations. Publications 2018, 6: 37, DOI: 10.3390/publications6030037.

19. CSE's White Paper on Promoting Integrity in Scientific Journa Publications. Available from: https://www.councilscienceeditors.org/wp-content/uploads/CSE-White-Paper_2018-update-050618.pdf (Accessed: 25.11.2020].

20. Core practices. Available from: https://publicationethics.org/ core-practices (Accessed: 25.11.2020).

21. Whetstone D, Moulaison-Sandy H. Quantifying authorship: A comparison of authorship rubrics from five disciplines. Proc Assoc Inf Sci Technol 2020; 57: e277, DOI: 10.1002/pra2.277.

22. Dance A. Authorship: Who's on first? Nature 2012; 489: 591-593, DOI: 10.1038/nj7417-591a.

23. Gasparyan AY, Ayvazyan L, Mukanova U, et al. Scientific Hypotheses: Writing, Promoting, and Predicting Implications. J Korean Med Sci 2019; 34: e300, DOI: 10.3346/jkms.2019.34.e300.

24. Gasparyan AY, Zimba O, Misra DP, Kitas GD. Monitoring Information Flow on Coronavirus Disease 2019 (COVID-19). Mediterr J Rheumatol 2020; 31 (Suppl 2): 243-246, DOI: 10.31138/ mjr.31.3.243.

25. Kovacs J. Honorary authorship epidemic in scholarly publications? How the current use of citation-based evaluative metrics make (pseudo)honorary authors from honest contributors of every multi-author article. J Med Ethics 2013; 39: 509-512.

26. Larivière V, Desrochers N, Macaluso B, et al. Contributorship and division of labor in knowledge production. Soc Stud Sci 2016; 46: 417-435, DOI: 10.1177/0306312716650046.

27. Wigington, PJ. Editorial: How to Determine Authorship Order J Am Water Resour Assoc 2017; 53: 987, DOI: 10.1111/17521688.12587

28. Mavis B, Durning SJ, Uijtdehaage S. Authorship Order in Medical Education Publications: In Search of Practical Guidance for the Community. Teach Learn Med 2019; 31: 288-297, DOI: 10.1080/10401334.2018.1533836

29. Khoshpouri P, Khoshpouri P, Beheshtian E, Yousem DM. The Policy of Co-First Authorship and Co-Senior Authorship in Radiology
Journals. J Am Coll Radiol 2019; 16: 1491-1498, DOI: 10.1016/ j.jacr.2019.06.011.

30. Lapidow A, Scudder P. Shared first authorship. J Med Libr Assoc 2019; 107: 618-620, DOI: 10.5195/jmla.2019.700.

31. Hong ST. Avoiding Inappropriate Authorship. J Korean Med Sci 2017; 32: 1046-1047, DOI: 10.3346/jkms.2017.32.6.1046.

32. Wislar JS, Flanagin A, Fontanarosa PB, Deangelis CD. Honorary and ghost authorship in high impact biomedical journals: a cross sectional survey. BMJ 2011; 343: d6128, DOI: 10.1136/ bmj.d6128.

33. Schroter S, Montagni I, Loder E, et al. Awareness, usage and perceptions of authorship guidelines: an international survey of biomedical authors. BMJ Open 2020; 10: e036899, DOI: 10.1136/bmjopen-2020-036899.

34. Hong ST. Unjustified Authorship Should Not Be Tolerated. J Korean Med Sci 2019; 34: e310, DOI: 10.3346/jkms.2019.34.e310.

35. Authorship for sale: Some journals willing to add authors to papers they didn't write. Available from: https://retractionwatch.com/2017/09/13/authorship-sale-journals-willing-addauthors-papers-didnt-write/ (Accessed: 25.11.2020).

36. Hackett R, Kelly S. Publishing ethics in the era of paper mills. Biol Open 2020; 9: bio056556, DOI: 10.1242/bio.056556.

37. Ross JS, Hill KP, Egilman DS, Krumholz HM. Guest authorship and ghostwriting in publications related to rofecoxib: a case study of industry documents from rofecoxib litigation. JAMA 2008; 299: 1800-1812, DOI: 10.1001/jama.299.15.1800.

38. Yadav S, Rawal G. Ghostwriters in the scientific world. Pan Afr Med J 2018; 30: 217, DOI: 10.11604/pamj.2018.30.217.16312.

39. Hayter M, Noyes J, Perry L, et al. Who writes, whose rights, and who's right? Issues in authorship. J Adv Nurs 2013; 69: 2599-2601, DOI: 10.1111/jan.12265.

40. Habibzadeh F. Judge the article, not the author. Croat Med J 2010; 51: 357-358, DOI: 10.3325/cmj.2010.51.357.

41. Cress PE. Why Do Academic Authors Need an ORCID ID? Aesthet Surg J 2019; 39: 696-697, DOI: 10.1093/asj/sjz042.

42. Gasparyan AY, Yessirkepov M, Gerasimov AN, et al. Scientific author names: errors, corrections, and identity profiles. Biochem Med (Zagreb) 2016; 26: 169-173.

43. Arunachalam S, Madhan M. Adopting ORCID as a unique identifier will benefit all involved in scholarly communication. Natl Med J India 2016; 29: 227-234.

44. Gasparyan AY, Nurmashev B, Yessirkepov M, et al. Researcher and Author Profiles: Opportunities, Advantages, and Limitations. J Korean Med Sci 2017; 32: 1749-1756, DOI: 10.3346/ jkms.2017.32.11.1749.

45. Gasparyan AY, Akazhanov NA, Voronov AA, Kitas GD. Systematic and open identification of researchers and authors: focus on open researcher and contributor ID. J Korean Med Sci 2014; 29: 1453-1456, DOI: 10.3346/jkms.2014.29.11.1453.

46. Mašić I, Begić E, Donev DM, et al. Sarajevo Declaration on Integrity and Visibility of Scholarly Publications. Croat Med J 2016; 57: 527-529, DOI: 10.3325/cmj.2016.57.527.

47. Zimba O, Radchenko O, Strilchuk L. Social media for research, education and practice in rheumatology. Rheumatol Int 2020; 40: 183-190, DOI: 10.1007/s00296-019-04493-4. 